\title{
Gambling Consumers in Thailand
}

\author{
Pannapa Changpetch ${ }^{1}$ \\ ${ }^{1}$ Department of Mathematical Sciences, Bentley University, USA \\ Correspondence: Pannapa Changpetch, Department of Mathematical Sciences, Bentley University, 175 Forest \\ Street, Waltham, MA, USA. Tel: 1-814-404-8255. E-mail: pchangpetch@bentley.edu
}

Received: March 6, 2017

doi:10.5539/ass.v13n5p136
Accepted: March 29, 2017 Online Published: April 19, 2017

URL: https://doi.org/10.5539/ass.v13n5p136

\begin{abstract}
This paper presents a study of household gambling consumption in Thailand in 2011. We investigate the nonlinear relationships between this behavior and household alcohol expenditure, household gambling expenditure, and demographic factors. We use Treenet to analyze datasets drawn from a socio-economic survey of 42,083 Thai households conducted in 2011. The results show that the five most significant variables in order of importance for predicting the likelihood of household gambling consumption are household income, household region, work status of the household head, religion of the household head, and age of the household head. In summary, the Treenet results suggest that the likelihood of gambling consumption was higher for households with an income of more than 25,000 Bahts per year, a location in the North, a Buddhist head of household, a head with active work status, a head between 35 and 55 years old, with household expenditure spent on alcohol consumed at home of more than 500 Bahts, with household expenditure spent on tobacco of more than 100 Bahts, and a head of household with less education.
\end{abstract}

Keywords: Alcohol expenditure, Gambling, Tobacco consumption, Treenet

\section{Introduction}

Gambling in Thailand involves many kinds of sources including the lottery, illegal lotteries, illegal casinos, and gambling on sports such as football (i.e., soccer), horse racing, and boxing. In terms of spending, a paper from the Thai Center for Gambling Studies (2015) estimates that around 370 billion Bahts circulated for both legal and illegal gambling activities in Thailand during the period of October 2014 to September 2015 (www.gamblingstudy-th.org). Gambling can cause social problems including depression, suicide, lost work or study time, and economic problems that necessitate public support programs (Madhusudhan, 1996; Szakmary \& Szakmary, 1995).

The literature includes several studies that investigate the association between the likelihood of household expenditure on gambling and socio-economic factors. In a study focusing on factors associated with household lottery expenditure across Canada, Kitchen and Powells (1991) showed that lottery expenditure increases as income increases; that lottery expenditure is significantly lower for households with female household heads; and that lottery expenditure declines as the head of household's educational level increases. Using a survey of household expenditure, Sawkins and Dickie (2002) investigated participation in and expenditure on the UK national lottery. They found that compared with all other demographic groups, those most likely to play the lottery are older males with only a basic school education who are in employment. Worthington et al. (2003) used regression modelling to predict gambling patterns in Australia based on a household expenditure survey with eight gambling categories. Their results show that age, ethnicity, and household composition each has a strong influence on the probability that a person will gamble, although the extent of the influence varies considerably across the gambling categories. Further, Tan et al. (2010) investigated factors associated with participation in gambling and expenditure in Malaysian households and found that non-Muslim households in Malaysia who are more likely to participate and spend more in gambling include Chinese, affluent, male-headed, older and non-white collars. According to the study, education and age play an important role in determining how likely Chinese households are to participate in gambling activity that is lower education and older population have higher likelihood to gamble.

The present study provides a thorough study of household gambling consumption in Thailand by focusing on nonlinear relationships between household gambling consumption, household alcohol expenditure, household 
tobacco expenditure, and demographic factors. We apply Treenet to analyze datasets drawn from a socio-economic survey of 42,083 Thai households in 2011. Our objective is to determine the characteristics of the households that are most likely to engage in gambling activity in order to target such households in efforts to reduce gambling in Thailand.

In this study, we implement a new method that has never been used before in this context, i.e., Treenet. We use this method because it can reveal non-linear associations between responses and predictors, which can, in turn, show the actual shape of the relationship between the predictor and the response (i.e., household gambling consumption) and for the entire range of the predictor without a linear association being assumed. This approach provides a more in-depth investigation into gambling consumption than is the case with standard approaches such as Logistic regression. Moreover, we also include household expenditure on alcohol and household expenditure on tobacco in our analysis. Note that this study draws on Changpetch et al.'s (2016) research using Treenet to investigate alcohol consumption in Thailand.

\section{Datasets}

We used a dataset collected via a socio-economic survey of 42,083 Thai households in 2011. The survey showed that $45.82 \%$ of Thai households participated in gambling in 2011. The factors included in our analysis are shown in Table 1. We used stratified two-stage sampling in the survey: our primary sampling units were blocks for municipal areas and villages for non-municipal areas, whereas our secondary sampling units were private households.

Table 1. Factors of Interest

\begin{tabular}{|c|c|}
\hline Predictor & Details for each predictor \\
\hline \multirow[t]{2}{*}{ Region } & Note: Region of household \\
\hline & $\begin{array}{l}\text { 1. Bangkok Metropolis }(5.84 \%), 2 \text {. Central (excluding Bangkok) }(29.21 \%), 3 \text {. North }(24.59 \%), 4 . \\
\text { Northeast }(25.92 \%) \text {, 5. South }(14.44 \%)\end{array}$ \\
\hline \multirow[t]{2}{*}{ Area } & Note: Area of household \\
\hline & 1. Municipal area $(61.13 \%), 2$. Non-municipal area $(38.87 \%)$ \\
\hline \multirow{2}{*}{$\begin{array}{l}\text { Number of household } \\
\text { members }\end{array}$} & Note: Number of members in household \\
\hline & Mean $=3.04$, Median $=3.00$, Standard deviation $=1.56$ \\
\hline \multirow[t]{2}{*}{ Income } & Note: Average monthly total income per household (Thai Baht) \\
\hline & Mean $=24,290$, Median $=15,616$, Standard deviation $=66,899$ \\
\hline \multirow[t]{2}{*}{ Sex } & Note: Sex of head of household \\
\hline & 1. Male (63.63\%), 2. Female $(36.37 \%)$ \\
\hline \multirow[t]{2}{*}{ Age } & Note: Age of head of household (years) \\
\hline & Mean $=52.66$, Median $=52.00$, Standard deviation $=14.92$ \\
\hline \multirow[t]{2}{*}{ Marital status } & Note: Marital status of head of household \\
\hline & 1. Single $(9.62 \%), 2$. Married $(66.64 \%), 3$. Widowed $(17.41 \%), 4$. Other $(6.33 \%)$ \\
\hline \multirow[t]{2}{*}{ Religion } & Note: Religion of head of household \\
\hline & 1. Buddhist $(94.95 \%), 2$. Islamic $(4.51 \%), 3$. Christian and other $(0.54 \%)$ \\
\hline \multirow[t]{2}{*}{ Disability } & Note: Whether head of household is disabled \\
\hline & 0. No $(97.31 \%), 1$. Yes $(2.69 \%)$ \\
\hline \multirow[t]{2}{*}{ Welfare } & Note: Whether head of household receives welfare or medical services \\
\hline & 0. No $(1.61 \%), 1$. Yes $(98.39 \%)$ \\
\hline Tobacco expenditure & $\begin{array}{l}\text { Note: Average monthly expenditure on tobacco products per household (Thai Baht) Mean }= \\
85.80 \text {, Median }=0.00 \text {, Standard deviation }=343.40\end{array}$ \\
\hline $\begin{array}{l}\text { Alcohol expenditure at } \\
\text { home }\end{array}$ & $\begin{array}{l}\text { Note: Average monthly expenditure on alcohol consumed at home per household (Thai Baht) } \\
\text { Mean }=67.30, \text { Median }=0.00, \text { Standard deviation }=345.80\end{array}$ \\
\hline $\begin{array}{l}\text { Alcohol expenditure } \\
\text { away from home }\end{array}$ & $\begin{array}{l}\text { Note: Average monthly expenditure on alcohol consumed away from home per household (Thai } \\
\text { Baht) Mean }=34.70 \text {, Median }=0.00 \text {, Standard deviation }=286.40\end{array}$ \\
\hline \multirow[t]{2}{*}{ Amount of debt } & Note: Total debt at end of previous month (Thai Baht) \\
\hline & Mean $=159,082$, Median $=6,000$, Standard deviation $=703,129$ \\
\hline \multirow[t]{2}{*}{ Government fund } & Note: Whether head of household borrowed money from a government fund \\
\hline & 0. No $(85.16 \%), 1$. Yes $(14.84 \%)$ \\
\hline
\end{tabular}




$\begin{array}{ll}\text { Education } & \text { Note: Educational level of head of household } \\ & \text { 0. Undefined }(5.78 \%), 1 \text {. Primary level }(58.42 \%), 2 \text {. Secondary level }(24.00 \%), 3 \text {. Higher than } \\ & \text { secondary level }(11.81 \%) \\ & \text { Note: Work status of head of household } \\ \text { Work status } & \text { 1. Employer }(4.61 \%), 2 . \text { Own-account worker }(36.91 \%), 3 \text {. Contributing family worker }(2.03 \%), \\ & \text { 4. Government employee }(10.33 \%), 5 \text {. State enterprise employee }(0.79 \%), 6 \text {. Private company } \\ & \text { employee }(21.63 \%), 7 \text {. Member of producers' cooperative }(0.03 \%), 8 . \text { Housewife }(4.58 \%), 9 . \\ & \text { Student }(0.73 \%), 10 . \text { Child or elderly person }(13.82 \%), 11 . \text { Ill or disabled person }(1.52 \%), 12 . \\ & \text { Looking for a job }(0.09 \%), 13 \text {. Unemployed }(0.44 \%), 14 \text {. Other }(2.48 \%)\end{array}$

Note that the average exchange rate was 37.88 Thai Bahts per US dollar in 2011.

\section{Method: Treenet}

In this section, we refine our understanding of household gambling consumption in the following way. Specifically, we applied data-mining models, which capture non-linearities. To demonstrate the techniques, we applied Treenet models (www.salford-systems.com/treenet.html; Freedman (2001)). The non-parametric approach adopted here makes it possible to handle a response variable with a large number of zero values. The model was used to analyze the relationships between household gambling consumption and the factors in Table 1 for the year 2011. The results of the Treenet analysis are shown in Table 2 and Figures 1-10. Note that Treenet derived the relative importance of the predictors (with the most important variable assigned an importance of 100 for reference), as shown in Table 2. Figures 1-10 display partial effects of each predictor on the predicted response (with other predictors held constant). The vertical axis represents half the log odds of gambling consumption, i.e., $1 / 2 * \log (\mathrm{p} /(1-\mathrm{p}))$, where $\mathrm{p}$ is the probability of gambling. The horizontal axis represents the value of the predictor. For simplicity, we used log odds to represent the vertical axis. The Treenet interpretation is based on a comparison of the relative values of log odds, i.e., the higher the value of the log odds the higher the probability or likelihood of gambling consumption. However, we cannot use the scale of the vertical axis to interpret the probability of gambling consumption, i.e., the zero value of the log odds, because Treenet does not imply that the probability of engaging in gambling is equal to the probability of not engaging in gambling.

\section{Results}

Table 2 shows in order of importance that the five most important variables for predicting the likelihood of household gambling consumption are household income, household region, the work status of the household head, the religion of the household head, and the age of the household head.

Table 2. Importance of Variables in the Treenet Model

\begin{tabular}{|c|c|c|}
\hline Variable & Score & \\
\hline INCOME & 100.00 & 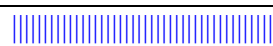 \\
\hline REGION & 89.61 & |||||||||||||||||||||||||||||||||||||| \\
\hline WORK_STATUS & 68.82 & |||||||||||||||||||||||||||||| $\mid$ \\
\hline RELIGION & 68.69 & |||||||||||||||||||||||||||| $\mid$ \\
\hline AGE & 59.98 & ||||||||||||||||||||||||| \\
\hline TOBACCO_EXPENDITURE & 54.69 & |||||||||||||||||||||||| \\
\hline EDUCATION_LEVEL & 46.87 & |||||||||||||||||| \\
\hline ALCOHOL_EXPENDITURE_HOME & 42.73 & ||||||||||||||||| \\
\hline NO_HOUSEHOLD & 40.26 & |||||||||||||| $\mid$ \\
\hline AMOUNT_DEBT & 39.93 & |||||||||||||||| \\
\hline ALCOHOL_EXPENDITURE_AWAY & 38.95 & |||||||||||||| $\mid$ \\
\hline GOVERNMENT_FUND & 37.31 & |||||||||||||| \\
\hline MARITAL_STATUS & 32.57 & |||||||||||| \\
\hline AREA & 19.47 & |||||| \\
\hline WELFARE & 10.81 & \|\| $\mid$ \\
\hline SEX & 8.75 & $\mid \|$ \\
\hline DISABILITY & 8.41 & || \\
\hline
\end{tabular}




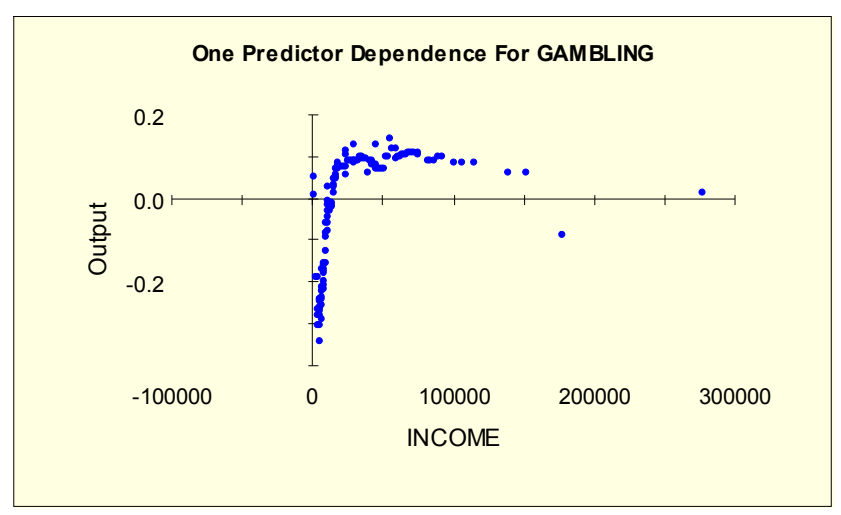

Figure 1. Household income and log odds of household gambling consumption

Figure 1 shows an upward relationship between household income and the log odds of household tobacco consumption until income reaches 25,000 Bahts, then a constant trend after income of 25,000 Bahts. It suggests that the likelihood of gambling consumption is higher for households with an income of more than 25,000 Bahts per year.

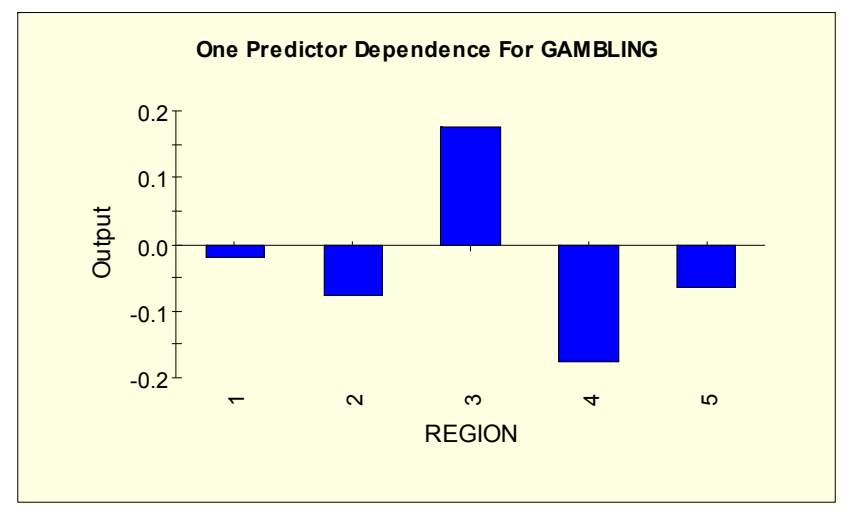

Figure 2. Household region and log odds of household gambling consumption

(Note that 1 = Bangkok Metropolis, $2=$ Central (excluding Bangkok), $3=$ North, $4=$ Northeast and $5=$ South)

Figure 2 shows that households in the North region have the highest log odds followed by households in Bangkok. This result means that households in the North are most likely to engage in gambling followed by households in the Bangkok region.

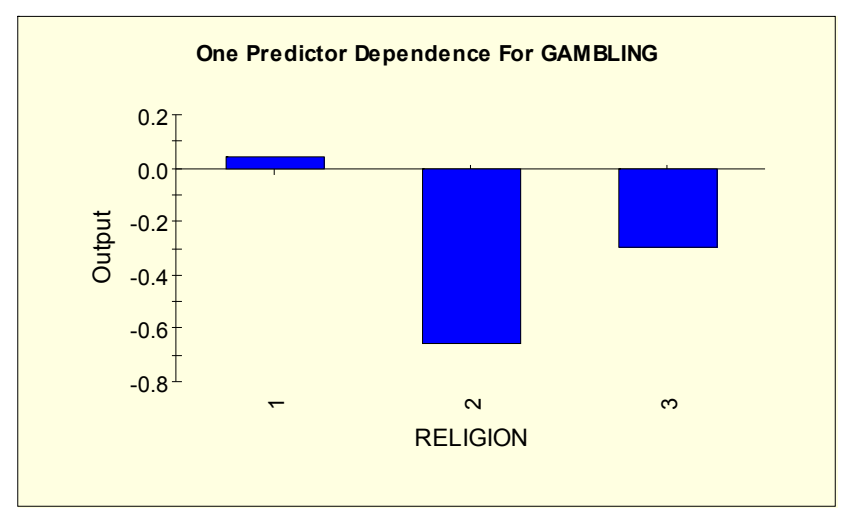

Figure 3. Religion of head of household and log odds of household gambling consumption (Note that $1=$ Buddhist, 2 = Islamic, $3=$ Christian and other)

Figure 3 shows that households with a Buddhist head have the highest log odds, which means these households are most likely to engage in gambling. On the other hand, for households with a Muslim head showed the lowest log odds, which means that these households are least likely to engage in gambling. 


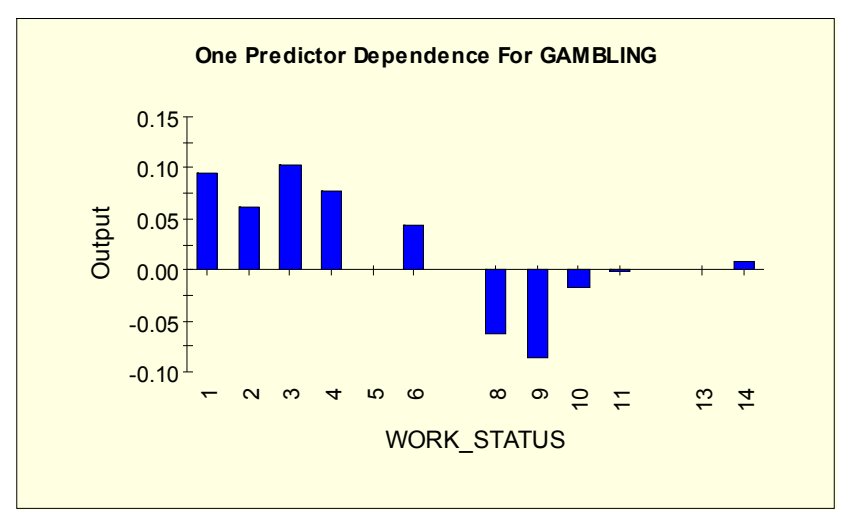

Figure 4. Work status of head of household and log odds of household gambling consumption.

(Note that $1=$ Employer, $2=$ Own-account worker, $3=$ Contributing family worker, $4=$ Government employee, 5

$=$ State enterprise employee, $6=$ Private company employee, $7=$ Member of producers' cooperative, $8=$

Housewife, $9=$ Student, $10=$ Child or elderly person, $11=$ Ill or disabled person, $12=$ Looking for a job, $13=$ Unemployed and $14=$ Other)

Figure 4 shows the positive association between the likelihood of gambling and households with a head of household with active work status (Status 1-7).

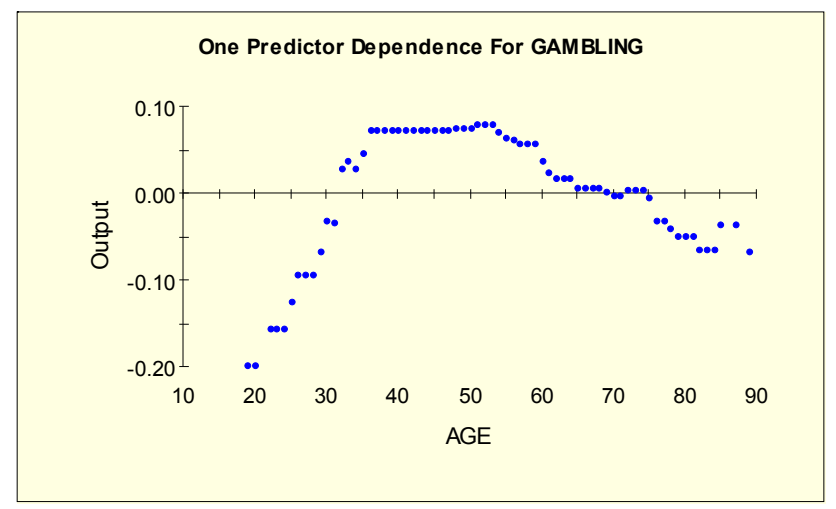

Figure 5. Age of head of household and log odds of household gambling consumption.

Figure 5 shows an upward linear relationship between the age of the household head and the log odds of household tobacco consumption until the age of 35 years and then a constant line until the age of approximately 55 years, followed by a downward trend after the age of approximately 55 years. This result implies that households with the heads of household aged between 35 and 55 are most likely to engage in gambling.

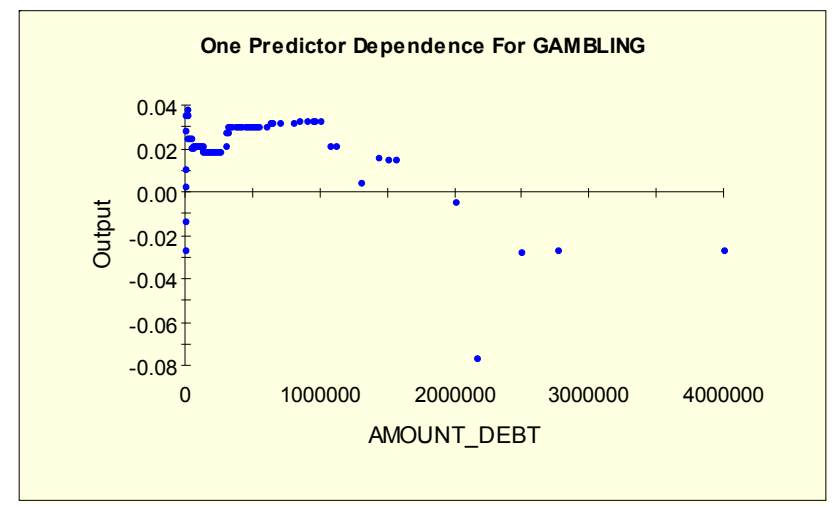

Figure 6. Amount of household debt and log odds of household gambling consumption.

Figure 6 shows a convex shape for debt between zero and 250,000 Bahts, then constant log odds until 1,000,000 Bahts, and then scattered downward afterwards. 


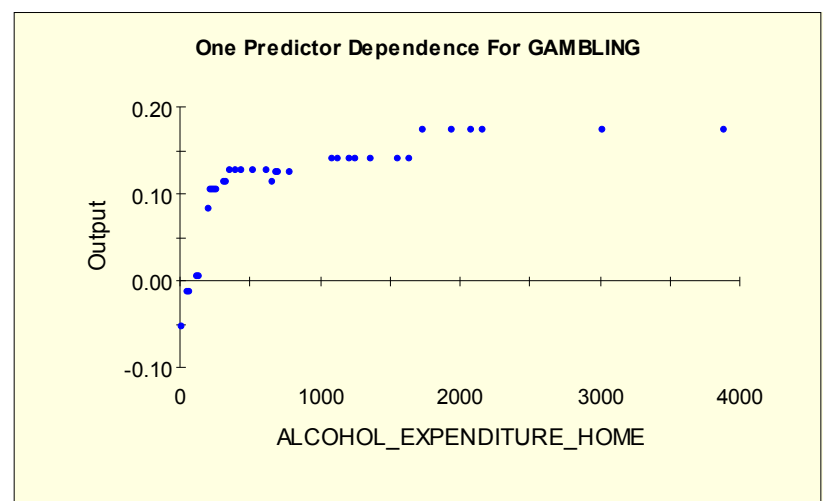

Figure 7. Household expenditure on alcohol consumed at home and log odds of household gambling consumption

Figure 7 shows an upward relationship between household expenditure on alcohol consumed at home and the log odds ratio of household gambling consumption until about 500 Bahts, then two small increasing steps afterwards.

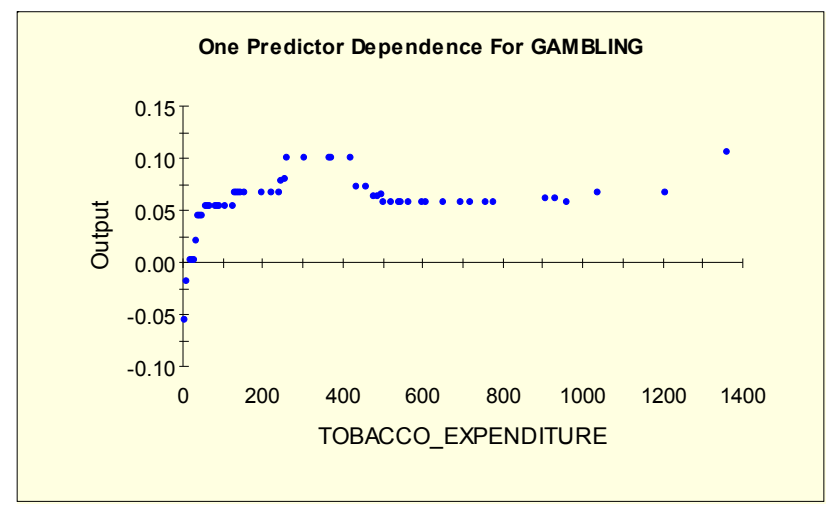

Figure 8. Household expenditure on tobacco and log odds of household gambling consumption

Figure 8 shows an upward curvilinear relationship between household expenditure on tobacco and the log odds ratio of household tobacco consumption until 100 Bahts, then a constant trend with the exception of a shift up and down between the expenditure of 250 Bahts and 400 Bahts.

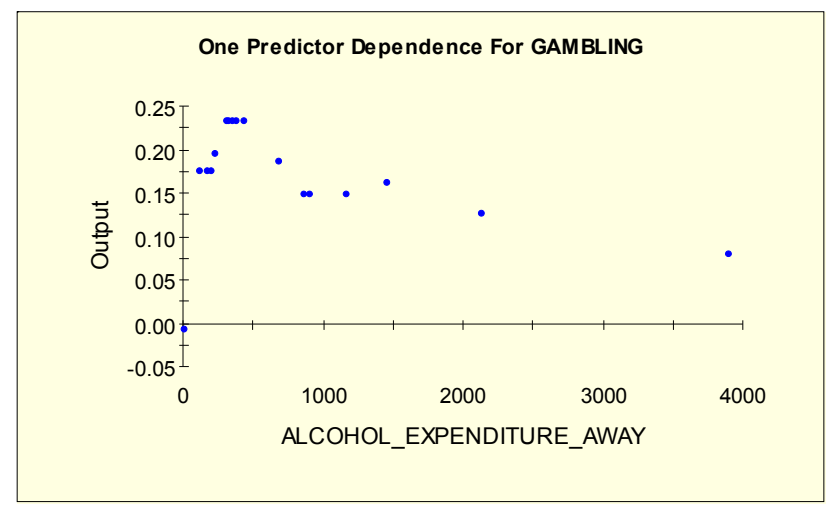

Figure 9. Household expenditure on alcohol consumed away from home and log odds of household gambling consumption

Figure 9 shows an upward relationship between household expenditure on alcohol consumed away from home and the log odds of household tobacco consumption until the former is at about $500 \mathrm{Bahts}$, at which point there is a drop in the log odds. 


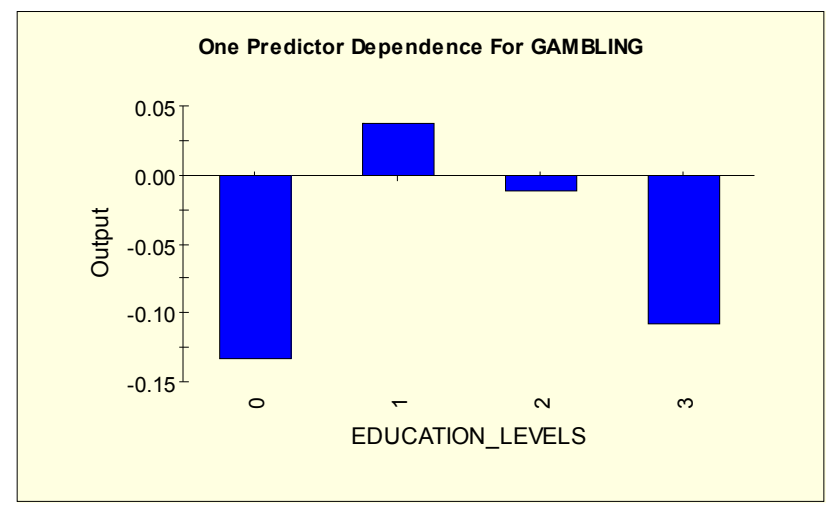

Figure 10. Educational level of head of household and log odds of household gambling consumption (Note that $0=$ Undefined, $1=$ Primary level, $2=$ Secondary level and 3. Higher than secondary level)

Figure 10 shows that the lower the educational level of the head of household the higher the log odds of household tobacco consumption.

Note that we do not include plots for the number of households, marital status, government fund, area, sex, welfare, or disability, as these showed very little association with the likelihood of household gambling consumption.

\section{Conclusion}

This paper provides a thorough study of household gambling consumption in Thailand in regard to the nonlinear relationships between household alcohol expenditure, household tobacco expenditure, and demographic factors. We applied Treenet to explore predictors associated with the likelihood of household gambling consumption to the analysis of datasets drawn from a socio-economic survey of 42,083 Thai households in 2011.

The result shows that the five most important variables in order of importance for predicting the likelihood of household gambling consumption are household income, household region, work status of the household head, religion of the household head, and age of the household head.

In summary, the Treenet results suggest that the likelihood of gambling consumption is higher for households with an income of more than 25,000 Bahts per year (while results reported by Tan et al., 2010) suggesting that the likelihood of gambling increases as household income increases), located in the North, with a Buddhist head of household, a head of household with active work status (which is similar to results reported by Sawkins \& Dickie, 2002), with a head between 35 and 55 years old (while results reported by Sawkins \& Dickie, 2002 and Tan et al., 2010), which suggest that older age increases the likelihood of gambling), with household expenditure of more than 500 Bahts on alcohol consumed at home, with household expenditure of more than 100 Bahts on tobacco, and a head of household with a low level of education (in line with results reported by Sawkins \& Dickie, 2002 and by Tan et al., 2010).

In regard to gender, several studies have reported a negative association between female head of household and the likelihood of household gambling (Sawkins \& Dickie, 2002; Tan et al., 2010). However, our study shows that this factor is not important in gambling consumption in Thailand meaning: there was no significant difference in terms of gambling consumption between households with a male head and those with a female head.

With this study, we contribute to the literature by using the Treenet technique to explore the nonlinear relationship between gambling and predictors. If we assume a linear relationship and use the standard technique of logistic regression, the result reported in the appendix shows that income and age are both insignificant (the $\mathrm{p}$-values for income and age are 0.426 and 0.364 , respectively). On the other hand, the use of Treenet facilitates an exploration across household income levels and the age of the household head to establish which give rise to the greatest likelihood of household gambling consumption. Also, through the nonlinear technique, we can establish the age range, i.e., from 35 to 55 years old, and the income level, i.e. more than 25,000 Bahts, most associated with household gambling. These specific findings should be helpful to policy makers responsible for tailoring programs to households most dependent on gambling in order to reduce gambling consumption in Thailand. 


\section{References}

Changpetch, P., Haughton, D., Le, M. T. X., Ly, S., Nguyen, A. D., Nguyen, P, \& Thach, T. T. (2016). Alcohol consumption in Thailand: A study of the associations between alcohol, tobacco, gambling, and demographic factors. Asian Journal of Social Sciences and Humanities, 5(4), 53-67.

Friedman, J. (2001). Greedy function approximation: A gradient boosting machine. Annals of Statistics, 29(5), 1189-1232. https://doi.org/10.1214/aos/1013203451

Kitchen, H., \& Powells, S. (1991). Lottery expenditures in Canada: A regional analysis of determinants and incidence. Applied Economics, 23(12), 1845-1852. https://doi.org/10.1080/00036849100000174

Madhusudhan, R. G. (1996). Betting on casino revenues: Lessons from state experiences. National Tax Journal, 401-412.

Sawkins, J. W., \& Dickie, V. A. (2002). National lottery participation and expenditure: Preliminary results using a two stage modelling approach. Applied Economics Letters, 9(12), 769-773. https://doi.org/10.1080/13504850210129441

Szakmary, A. C., \& Szakmary, C. M. (1995). State lotteries as a source of revenue: A re-examination. Southern Economic Journal, 1167-1181. https://doi.org/10.2307/1060748

Tan, A. K., Yen, S. T., \& Nayga, Jr., R. M. (2010). Socio-demographic determinants of gambling participation and expenditures: Evidence from Malaysia. International Journal of Consumer Studies, 34(3), 316-325. https://doi.org/10.1111/j.1470-6431.2009.00856.x

Worthington, A., Brown, K., Crawford, M., \& Pickernell, D. (2003). Socio-Economic and Demographic Determinants of Household Gambling in Australia (Vol. 156). School of Economics and Finance, Queensland University of Technology.

\section{Appendix: Logistic regression for gambling consumption in 2011}

\begin{tabular}{|c|c|c|c|c|c|}
\hline & coefficient & $\mathrm{p}$-value & & coefficient & p-value \\
\hline constant & -1.194 & & religion & & \\
\hline number_household & 0.10714 & 0.000 & 2 & -2.4551 & 0.000 \\
\hline income & 0 & 0.426 & 3 & -1.139 & \\
\hline age & -0.00095 & 0.364 & work_status_original & & \\
\hline region & & & $-2^{-}$ & -0.2081 & 0.000 \\
\hline 2 & -0.0597 & 0.000 & 3 & -0.1523 & \\
\hline 3 & 0.3977 & & 4 & -0.0075 & \\
\hline 4 & -0.3553 & & 5 & -0.207 & \\
\hline 5 & -0.0687 & & 6 & -0.2311 & \\
\hline area & & & 7 & -1.229 & \\
\hline 2 & -0.0828 & 0.000 & 8 & -0.4257 & \\
\hline sex & & & 9 & -2.543 & \\
\hline 2 & -0.0232 & 0.370 & 10 & -0.644 & \\
\hline marital_status & & & 11 & -0.543 & \\
\hline $2^{-}$ & 0.2974 & 0.000 & 12 & -0.686 & \\
\hline 3 & 0.2214 & & 13 & -0.438 & \\
\hline 4 & 0.2926 & & 14 & -0.2476 & \\
\hline education & & & amount_debt & 0 & 0.849 \\
\hline 2 & 0.5448 & 0.000 & disability & & \\
\hline 3 & 0.5095 & & 1 & -0.0483 & 0.482 \\
\hline 4 & 0.5023 & & welfare & & \\
\hline 5 & 0.3779 & & 1 & 0.3491 & 0.000 \\
\hline 6 & 0.2921 & & government_fund & & \\
\hline 7 & 0.231 & & $1^{-}$ & 0.3137 & 0.000 \\
\hline 8 & -1.248 & & alcohol-home & 0.001177 & 0.000 \\
\hline \multirow[t]{2}{*}{9} & -2.26 & & alcohol-away & 0.001075 & 0.000 \\
\hline & & & tobacco-monthly & 0.000245 & 0.000 \\
\hline
\end{tabular}

\section{Copyrights}

Copyright for this article is retained by the author(s), with first publication rights granted to the journal.

This is an open-access article distributed under the terms and conditions of the Creative Commons Attribution license (http://creativecommons.org/licenses/by/4.0/). 